\title{
Humans can create themselves, become individual, and have confidence by creating things
}

\author{
Yoshiki Hirooka ${ }^{1}$
}

Received: 9 April 2021 / Accepted: 13 April 2021

(c) The Japan Society of Ultrasonics in Medicine 2021

If there was one thing that would cause me to doubt that human beings are good by nature, I think it would be the existence of envy in the human heart. This is because envy generally harms good things in an insidious and covert way.

Love and envy are the most conniving of the gamut of human emotions. They tend to persist much longer than the other emotions, which open the door to intellectual machinations. And I think that these emotions are in turn prolonged by the intellectual machinations. No other emotion hurts human beings as much as love and envy. This is because the other emotions do not last as long.

People feel envy towards those with a higher status than themselves and those who are happier than they are. However, the emotion is based on the assumption that the difference is not absolute, and that you could potentially be like them. Moreover, the way that envy usually works is not you raising yourself up to the level of the person you envy, but rather to bring that person down to your level. Envy is a tendency for people who do not know that "all people are equal before God" to seek equalization in the human realm.

It is likely correct to say that envy occurs due to a lack of confidence. Then again, it seems like feelings of envy could not arise if one has no confidence at all. However, people feeling envy usually avoid what they envy in another person and bring up something else. Envy is deceptive in nature.

The following is a quote from Teru Miyamoto's novel titled The Garden of Skeleton Building:

"The darkest and most malicious form of envy that a person can harbor is that of another's uprightness and magnificence".
It is said that having confidence is key to eliminating feelings of envy. Confidence is a product of making thinks by yourself. In contrast, nothing is created from envy. Human beings create their self-identity and form their individuality by making things. It seems that the more individualistic a person is the less envious they are. This is the reason for the saying "There is no happiness without individuality".

This year's second issue of JMU includes the feature "Everything you need to know about ultrasound for diagnosis of gallbladder diseases", which was put together by Prof. Okaniwa. JMU features are designed so that authors who are going to write papers in a certain field can familiarize themselves with almost all of the latest basic information by simply reading the applicable feature. By familiarizing themselves with the contents in this issue's feature, those who are planning to write papers related to ultrasonic diagnosis of gallbladder diseases can gain the necessary and sufficient preliminary knowledge for that purpose. We are confident that this is a wonderful feature. In our next and subsequent issues, we plan on publishing features that will directly help our readers write papers. We hope that you very much look forward to reading them.

The JMU Editorial Board will do its utmost again this year to publish articles that will be helpful to all of our readers. Thank you for your continued support.

Publisher's Note Springer Nature remains neutral with regard to jurisdictional claims in published maps and institutional affiliations.
Yoshiki Hirooka

hirooka@med.nagoya-u.ac.jp

1 Department of Gastroenterology and Hepatology, Fujita Health University, Aichi, Japan 